\title{
Bleeding during laparoscopic partial nephrectomy: Can a hemostatic matrix help to improve hemostasis?
}

\author{
Faruk Ozgor, Abdulmuttalip Simsek, Ozgu Aydogdu, Onur Kucuktopcu, Omer Sarilar, Ahmet Yalcin \\ Berberoglu, Mehmet Fatih Akbulut, Murat Binbay \\ Department of Urology, Haseki Teaching and Research Hospital, Istanbul, Turkey.
}

\begin{abstract}
Summary Objectives: To evaluate the possible role of an hemostatic matrix on hemostasis, perioperative outcomes and complications in patients who underwent laparoscopic partial nephrectomy (LPN).

Materials and methods: Patients charts were analyzed retrospectively and their demographic characteristics, operative parameters and follow-up results were recorded. Patients were divided into two groups, according to those who used an hemostatic matrix as Group $1(n=41)$ and those who did not used as Group $2(n=44)$. Demographic characteristics of patients, tumor features, operation time, clamping of the renal vessels, ischemia time, suturing of the collecting system, perioperative hemorrhage and complications were evaluated. Histopathological results, surgical margin status, creatinine level and recurrence at the $3^{\text {rd }}$ month of follow up were analyzed. Statistical analyses were performed with SPSS 17.0 and significance was set at $p$ value of $<0.05$.

Results: The mean RENAL nephrometry score was $5.9 \pm 2.0$ and the mean tumor size was $35 \pm 12 \mathrm{~mm}$. All patients had a single tumor and 44 of them had a tumor in the right kidney. The renal artery was clamped in 79 cases and the mean ischemia time was $20.1 \pm 7$ minutes. The mean tumor size and the mean RENAL nephrometry score was statistically higher in Group 1 ( $p: 0.016$ and $p<0.001$, respectively). Pelvicaliceal repair was more common in Group 1 due to deeper extension of tumors in this group ( $p$ : 0.038). In Group 1 , less hemorrhage and blood transfusion requirement, with shorter ischemia and operation time was detected.

Conclusion: The outcomes of the recent study showed that adjunctive use of an hemostatic matrix improves hemostasis and decreases hemorrhagic complications during LPN.

Further prospective studies are required to assess the potential role of an hemostatic matrix in LPN.
\end{abstract}

KEY WORDS: Hemostatic matrix; Partial nephrectomy; Renal cell cancer.

Submitted 6 December 2015; Accepted 31 March 2016

\section{INTRODUCTION}

Previous studies demonstrated that nephron-sparing surgery has similar oncologic outcomes in selected patients when compared to radical nephrectomy $(1,2)$. Laparoscopic partial nephrectomy (LPN) is a minimally invasive nephron sparing technique with favorable renal function outcomes, shorter hospital stay and decreased postoperative analgesic use (3). However, LPN is a technical challenging procedure and associated with poten- tial complications including urinary leakage and bleeding requiring transfusion (4). Since LPN was firstly reported, several techniques for tumor excision and hemostasis have been investigated to achieve a bloodless operative field for precise tumor excision is an acceptable ischemia time and with the least possible deterioration of renal function (5). However, use of the suture techniques is time consuming and may cause additional tissue damage (6). Some renal hemostatic agents have been previously described for use during LPN, to improve hemostasis and decrease complication rates. However, there is no consensus on the routine use of hemostatic agents during LPN. In a recent study, we aimed to investigate the possible role of an hemostatic matrix FloSeal ( ${ }^{\circledR}$ FloSeal Baxter Healthcare Corporation) on hemostasis, perioperative outcomes and complications in patients who underwent laparoscopic partial nephrectomy (LPN).

\section{MATERIAL AND METHOdS}

In our clinic, laparoscopic partial nephrectomy (LPN) for renal tumours was performed in 85 patients by a single surgeon between May 2009 and February 2014. In patients with organ confined renal tumours with up to 7 $\mathrm{cm}$ in size, without lymph node and venous involvement, LPN was performed. Informed consent was obtained from all the patients.

Patients' charts were analyzed retrospectively and their demographic characteristics, operative parameters and follow-up results were recorded.

Patients were divided into two groups, according to those who used FloSeal as Group $1(n=41)$ and those who did not used as Group $2(n=44)$.

A transperitoneal technique in the extended flank position with three trocars was preferred in all the patients. If necessary, additional trocar was inserted for liver or spleen retraction and re-postioning of the kidney. After incision of the Todt line, dissection continued medially to expose the renal artery and vein. Endoscopic bulldog clamps were used to interrupt blood flow, and peripheral small lesions were resected without hilar clamping. Partial nephrectomy was performed with monopolar scissors. Major transected intrarenal were stiched up with eight sutures, while renal parenchymal hemorrhage was kept.

Prepackaged hemostatic agent with a combination of 1.5 
$\mathrm{ml}$ of bovine gelatin matrix and 5000 US of bovinederived thrombin.

This syringe was applied with an application device introduced into the abdomen through a laparoscopic port.

The renal artery was then unclamped to terminate warm ischemia.

Demographic characteristics of the patients and tumor features were compared between the two groups. Intraoperative parameters including operation time, clamping of the renal vessels, ischemia time, suturing of the collecting system, perioperative hemorrhage and complications were also evaluated.

Hemorragic complication was defined as bleeding leading to convert open surgery or radical nephrectomy and intraoperative or postoperative bleeding requiring transfusion. Histopathological results, surgical margin status, creatinine level and recurrence at the 3rd month of follow up were also analyzed.

\section{Statistical analysis}

Statistical analyses were performed with SPSS 17.0 (New York, USA).

Results were described as numbers, means, standard deviations and percentages. Comparisons were performed by the chi square test, Student $\mathrm{t}$ test and Mann Whitney U test.

Significance was set at $\mathrm{p}$ value of $<0.05$.

Table 1.

Preoperative demographic data of patients.

\begin{tabular}{|lcc|}
\hline & N & Percentage (\%) \\
\hline Gender & 50 & $58.8 \%$ \\
Male & 35 & $41.2 \%$ \\
\hline Female & $52.2+/-27.7$ & \\
\hline Mean follow up time (months) & $24.7+/-3.0$ & \\
\hline Mean BMI (kg/m²) & & \\
\hline ASA score & 52 & $61.2 \%$ \\
1 & 25 & $29.4 \%$ \\
2 & 8 & $9.4 \%$ \\
3 & & \\
\hline Comorbidities & 50 & \\
None & 24 & \\
Hypertension & 19 & \\
Diabetes mellitus & 6 & \\
Coronary arterial disease & 5 & \\
Chronic obstructive pulmonary disease & & \\
\hline Smoking & 53 & $62.4 \%$ \\
Yes & 32 & $37.6 \%$ \\
No & & \\
\hline Radiological tumor location & 42 & $49.4 \%$ \\
Lower pole & 31 & $36.5 \%$ \\
Middle pole & 12 & $14.1 \%$ \\
Upper pole & & \\
\hline Complaint & 34 & $40 \%$ \\
Follow up & 1 & $1.2 \%$ \\
Lower urinary tract symptoms & 1 & $1.2 \%$ \\
Weakness & $2.4 \%$ \\
Hematuria & 9 & $42.4 \%$ \\
Weight loss & 2 & \\
Abdominal pain & 2 & \\
Flank pain & 36 & \\
\hline Mean R.E.N.A.L. score & $5.9+/-2.0$ & \\
\hline Mean tumor size (millimeters) & $35+/-12$ & \\
\hline
\end{tabular}

\section{RESULTS}

The mean age and the mean BMI of all patients were $58.8+/-10.9$ years old and $24.7+/-3.0 \mathrm{~kg} / \mathrm{m} 2$.

All patients had a single tumour and 44 of them had a tumour in the right kidney. Eight patients had an ASA score of three, while hypertension and diabetes mellitus were the most common comorbidities.

The mean RENAL nephrometry score was $5.9 \pm 2.0$ and the mean tumor size was $35 \pm 12 \mathrm{~mm}$.

Demographic data are listed in Table 1.

FloSeal was used in 41 patients and wedge resection was

Table 2.

Perioperative and post operative data of patients.

\begin{tabular}{|c|c|c|}
\hline & $\mathrm{N}^{\circ}$ & Percentage $(\%)$ \\
\hline Mean preoperative hemoglobin $(\mathrm{g} / \mathrm{dl})$ & $13.0+/-1.3$ & \\
\hline Mean preoperative creatinine $(\mathrm{mg} / \mathrm{dl})$ & $1.09+/-0.35$ & \\
\hline Mean postoperative day one hemoglobin (g/dl) & $12.0+/-1.5$ & \\
\hline Mean postoperative creatinine at $3^{\text {rd }}$ month $(\mathrm{mg} / \mathrm{dl})$ & $1.07+/-0.3$ & \\
\hline \multicolumn{3}{|l|}{ Side } \\
\hline Left & 41 & $48.2 \%$ \\
\hline Right & 44 & $51.8 \%$ \\
\hline \multicolumn{3}{|l|}{ Tumor extraction technique } \\
\hline Wedge resection & 79 & $92.9 \%$ \\
\hline Enucleation & 6 & $7.1 \%$ \\
\hline \multicolumn{3}{|l|}{ Hemostatic agent usage } \\
\hline Yes & 41 & $48.2 \%$ \\
\hline No & 44 & $51.8 \%$ \\
\hline \multicolumn{3}{|l|}{ Suturing of the collecting system } \\
\hline Yes & 28 & $32.9 \%$ \\
\hline No & 57 & $67.1 \%$ \\
\hline \multicolumn{3}{|l|}{ Turning to open surgery } \\
\hline Yes & 4 & $4.7 \%$ \\
\hline No & 81 & $95.3 \%$ \\
\hline \multicolumn{3}{|l|}{ Blood transfusion need } \\
\hline Yes & 11 & $12.9 \%$ \\
\hline No & 74 & $87.1 \%$ \\
\hline Mean perioperative hemorrhage (ml) & $153.6+/-50.2$ & \\
\hline Mean operation time (minutes) & $136.7+/-55.3$ & \\
\hline \multicolumn{3}{|l|}{ Perioperative complications } \\
\hline Hemorrhage & 5 & $5.9 \%$ \\
\hline \multicolumn{3}{|l|}{ Clavien complications } \\
\hline 0 & 70 & $82.4 \%$ \\
\hline 1 & 10 & $11.8 \%$ \\
\hline 2 & 2 & $2.4 \%$ \\
\hline 3 & 3 & $3.6 \%$ \\
\hline Mean ischemia time (minutes) & $20.1+/-7$ & \\
\hline Mean hospitalization time (days) & $3.5+/-1.6$ & \\
\hline \multicolumn{3}{|l|}{ Histology } \\
\hline Angiomyolipoma & 13 & $15.3 \%$ \\
\hline Complicated cyst & 1 & $1.2 \%$ \\
\hline Oncocytoma & 3 & $3.5 \%$ \\
\hline Renal cell cancer & 68 & $80 \%$ \\
\hline \multicolumn{3}{|l|}{ Grade of RCC } \\
\hline 1 & 42 & \\
\hline 2 & 21 & \\
\hline 3 & 6 & \\
\hline \multicolumn{3}{|l|}{ Pathological stage } \\
\hline T1a & 65 & $76 \%$ \\
\hline $\mathrm{T} 1 \mathrm{~b}$ & 18 & $21.2 \%$ \\
\hline Т2 & 2 & $2.4 \%$ \\
\hline \multicolumn{3}{|l|}{ Surgical margin } \\
\hline Negative & 83 & \\
\hline Positive & 2 & \\
\hline \multicolumn{3}{|l|}{ Recurrance at $3^{\text {rd }}$ month follow up } \\
\hline Yes & 0 & \\
\hline № & 85 & \\
\hline
\end{tabular}


Table 3

Comparison of patients according to perioperative hemostatic agent usage.

the most common technique for partial nephrectomy. The renal artery was clamped in 79 cases and the mean ischemia time was $20.1 \pm 7$ minutes.

The mean perioperative hemorrhage was 153.6+/-50.2 $\mathrm{ml}$ and blood transfusion was required in 11 patients. Suturing of the collecting system was performed in 28 patients. The most common histopathology was renal cell carcinoma and angiomyolipoma. Patients' preoperative data and pathological results are detailed in Table 2. The mean tumor size and the mean RENAL nephrometry score was statistically higher in Group 1 ( $\mathrm{p}=0.016$ and $\mathrm{p}<0.001$, respectively).

Pelvicaliceal repair was more common in Group 1 due to deeper extension of tumors in this group (p: 0.038).

In Group 1, use of FloSeal provided better bleeding control with less hemorrhage and blood transfusion requirement. Because of the less stiches requirement in group 1 , the mean ischemia time and the time operation were 18.2 and 115.6 minutes, respectively and these parameters were shorter in group 1 when compared with Group $2(\mathrm{p}=0.038)$. None of the laparoscopic procedures in Group 1 was converted to open surgery whereas in Group 2, four patients were converted to open surgery due to uncontrolled bleeding in two, decision for radical nephrectomy in one and technique difficulty in one. Comparison between the two groups is summarized in Table 3 .

\section{Discussion}

Although previous studies have shown that LPN is a feasible and effective minimally invasive technique in the surgical treatment of selected patients with renal tumors, its potential risk of bleeding requiring transfusion is well known $(7,8)$. Bleeding should be minimized to avoid hypovolemia, anemia, hemodynamic deterioration and exposure to the risk of transfusion (9). It is also important to achieve optimal visualization of the surgical site to enabling an acceptable ischemia time and oncologic outcome (10). Control of bleeding in LPN, is an active area of investigation since uncontrolled hemorrhage negatively affects the mortality and morbidity rates, as well as the convalescence period.

Traditional surgical methods including suture, energy based coagulation systems, ligature and hemostatic clips can be used to handle bleeding $(12,13)$.

Available hemostatic agents include absorbable hemostats such as gelatin, collagen and oxidized regenerated cellulose and active hemostats such as thrombin and fibrin sealants (16).

Fibrin sealants were reported as easy to use but not effective in dealing with major vascular injury.

Therefore, a combination of different hemostasis methods has been investigated (17).

In a previous study the authors compared seven hemostatic agents in an animal partial nephrectomy model (17). The authors concluded that hemostatic agents were

\begin{tabular}{|c|c|c|c|}
\hline & \multicolumn{2}{|c|}{ Hemostatic agent usage } & \multirow[b]{2}{*}{$P$ value } \\
\hline & Yes & No & \\
\hline Number & 41 & 44 & \\
\hline Mean age (years) & 56.8 & 60.7 & 0.101 \\
\hline Mean follow up time (months) & $39+/-17.2$ & $64.4+/-24.5$ & $<0.001$ \\
\hline Mean BMI $\left(\mathrm{kg} / \mathrm{m}^{2}\right)$ & 25.2 & 24.3 & 0.169 \\
\hline ASA score & & & 0.365 \\
\hline Tumor size (mm) & 38.2 & 32 & 0.016 \\
\hline Mean R.E.N.A.L. score & 6.8 & 5.1 & $<0.001$ \\
\hline Mean hemoglobin drop (g/dl) & 1.01 & 1.07 & 0.842 \\
\hline Mean creatinine level change $(\mathrm{mg} / \mathrm{dl})$ & 0.04 & -0.02 & 0.143 \\
\hline Mean perioperative hemorhhage (ml) & 132.9 & 172.9 & $<0.001$ \\
\hline Mean operation time (minutes) & 115.6 & 156.4 & $<0.001$ \\
\hline Mean ischemia time (minutes) & 18.2 & 21.9 & 0.013 \\
\hline Mean hospitalization time (days) & 3.4 & 3.6 & 0.555 \\
\hline \multicolumn{4}{|l|}{ Comorbities } \\
\hline None & 27 & 23 & 0.399 \\
\hline Hypertension & 9 & 13 & \\
\hline Diabetes mellitus & 8 & 10 & \\
\hline Coronary arterial disease & 0 & 5 & \\
\hline Chronic obstructive pulmonary disease & 2 & 3 & \\
\hline Complaint & & & 0.151 \\
\hline Follow up & 19 & 15 & \\
\hline Lower urinary tract symptoms & 0 & 1 & \\
\hline Weakness & 1 & 0 & \\
\hline Hematuria & 1 & 8 & \\
\hline Abdominal pain & 1 & 1 & \\
\hline Flank pain & 17 & 19 & \\
\hline \multicolumn{4}{|l|}{ Smoking } \\
\hline Yes & 23 & 30 & 0.251 \\
\hline № & 18 & 14 & \\
\hline \multicolumn{4}{|l|}{ Radiological tumor location } \\
\hline Lower pole & 18 & 24 & \\
\hline Middle pole & 17 & 14 & \\
\hline Upper pole & 6 & 6 & \\
\hline Tumor extraction technique & & & 0.108 \\
\hline Wedge resection & 40 & 39 & \\
\hline Enucleation & 1 & 5 & \\
\hline Turning to open surgery & & & 0.048 \\
\hline Yes & 0 & 4 & \\
\hline № & 41 & 40 & \\
\hline Blood transfusion need & & & 0.005 \\
\hline Yes & 1 & 10 & \\
\hline No & 40 & 34 & \\
\hline Clamping of the renal vessels & & & 0.112 \\
\hline Yes & 36 & 43 & \\
\hline No & 5 & 1 & \\
\hline Perioperative complication & & & 0.084 \\
\hline Hemorrhage & 0 & 5 & \\
\hline Clavien complications & & & 0.422 \\
\hline 0 & 35 & 35 & \\
\hline 1 & 4 & 6 & \\
\hline 2 & 1 & 1 & \\
\hline 3 & 1 & 2 & \\
\hline Histology & & & 0.264 \\
\hline Angiomyolipoma & 7 & 6 & \\
\hline Complicated cyst & 0 & 1 & \\
\hline Oncocytoma & 0 & 3 & \\
\hline Renal cell cancer & 34 & 34 & \\
\hline Grade of RCC & & & 0.044 \\
\hline 1 & 16 & 26 & \\
\hline 2 & 15 & 6 & \\
\hline 3 & 3 & 3 & \\
\hline Pathological stage & & & 0.298 \\
\hline T1a & 29 & 36 & \\
\hline$\overline{\mathrm{T} 1 \mathrm{~b}}$ & 10 & 8 & \\
\hline$\overline{\mathrm{T} 2}$ & 2 & 0 & \\
\hline Surgical margin & & & 0.960 \\
\hline Negative & 40 & 43 & \\
\hline Positive & 1 & 1 & \\
\hline
\end{tabular}


effective for small vascular injuries. However, sutured bolsters were required for large partial nephrectomies. Hutchinson et al. (11) evaluated the effectiveness of fibrin pad consisting of human thrombin and fibrinogen delivered to the targeted site by an absorbable synthetic matrix in an animal model. The authors have demonstrated that fibrin pad was as effective as conventional methods for the primary management of severe bleeding without the need for hilar control with a shorter operative time.

Dalpiaz et al. (19) reviewed the use of hemostatic agents in 15 animal model studies and 11 clinical trials concluding that fibrin sealants were effective in both animal and clinical studies. Richter et al. and Bak et al. $(20,21)$ investigated the use of FloSeal in LPN in two different studies. In both studies no renal suturing was used, none of the patients underwent pelvicaliceal repair and none of the patients required blood transfusions. Gill et al. (6) evaluated the use of FloSeal during LPN.

The authors found that the adjunctive use of FloSeal substantially enhanced parenchymal hemostasis and decreased the procedural and hemorrhagic complications.

LPN with the use of FloSeal is a feasible and safe method for the treatment of small renal tumour.

FloSeal facilitates the conversion of fibrinogen to fibrin and creates an insoluble fibrin clot acting as a hemostatic sealant. FloSeal includes gelatin granules, which swell in case of hemorrhage and mechanically control the bleeding by creating a composite hemostatic plug. FloSeal can be injected through a single laparoscopic port with a short application time and does not require a completely dry surgical field to be effective.

Disadvantages of FloSeal include cost, possible allergic reactions and potential transmission of prion diseases (22). In the present study, FloSeal was used as single hemostatic agent in all the patients. None of the patients experienced adverse effect associated with FloSeal. Suturing was used for renal collecting system repair, in case of major transected intrarenal vessels and severe parenchymal hemorrhage.

Intraoperatively, hemostasis was sufficient in all the patients. Mean tumor size and mean warm ischemia time were $35+/-12 \mathrm{~mm}$ and $20.1+/-7$ minutes, respectively. These were comparable with previous studies $(4,5,17)$. Previous studies described an association between the depth of tumor invasion and rate of hemorrhage.

Ramani et al. (22) investigated complications associated with LPN and showed that 53\% of 19 patients requiring transfusion due to hemorrhage had deep tumors.

In this study, the FloSeal group tended toward significantly fewer hemorrhagic complications although the depth of tumor invasion was higher. Our findings showed that FloSeal provides better bleeding control with less hemorrhage and blood transfusion requirements, with significantly shorter operation and warm ischemia time. Although our findings support previous trials advocating that FloSeal is a safe and effective hemostatic agent, we think that it should be used as an adjunctive method in conjunction with suturing techniques, for major bleedings from large vessels or renal parenchyma. Although the current study is one of the rare studies investigating the use of FloSeal as a hemostatic agent in LPN, it has some limitations including its retrospective design and relatively small number of patients.

In conclusion, FloSeal is a safe,reliable and effective hemostatic agent, which can be used during LPN to avoid hemorrhagic complications. FloSeal may potentially enhance the technique of LPN and help the surgeon to perform the procedure more comfortably. Further prospective, randomized and controlled studies are required to evaluate the potential role of FloSeal in LPN.

\section{REFERENCES}

1. Belldegrun A, Tsui KH, deKernion JB, Smith RB. Efficacy of nephron-sparing surgery for renal cell carcinoma: analysis based on the new 1997 tumor-node-metastasis staging system. J Clin Oncol. 1999; 17:2868-75.

2. Fergany AF, Hafez KS, Novick AC. Long-term results of nephron sparing surgery for localized renal cell carcinoma: 10-year followup. J Urol. 2000; 163:442-5.

3. Gill IS, Matin SF, Desai MM, et al. Comparative analysis of laparoscopic versus open partial nephrectomy for renal tumors in 200 patients. J Urol. 2003; 170:64-8.

4. Wille AH, Johannsen M, Miller K, Deger S. Laparoscopic partial nephrectomy using FloSeal for hemostasis: technique and experiences in 102 patients. Surg Innov. 2009; 16:306-12.

5. Breda A, Stepanian SV, Lam JS, et al. Use of haemostatic agents and glues during laparoscopic partial nephrectomy: a multi-institutional survey from the United States and Europe of 1347 cases. Eur Urol. 2007; 52:798-803.

6 Gill IS, Ramani AP, Spaliviero M, et al. Improved hemostasis during laparoscopic partial nephrectomy using gelatin matrix thrombin sealant. Urology. 2005; 65:463-6.

7. Lam JS, Shvarts O, Pantuck AJ. Changing concepts in the surgical management of renal cell carcinoma. Eur Urol. 2004; 45:692705 .

8. Mabjeesh NJ, Avidor Y, Matzkin H. Emerging nephron sparing treatments for kidney tumors: a continuum of modalities from energy ablation to laparoscopic partial nephrectomy. J Urol. 2004; 171:553-60.

9. Winfield HN, Donovan JF, Godet AS, Clayman RV. Laparoscopic partial nephrectomy: initial case report for benign disease. J Endourol. 1993; 7:521-6.

10. Andonian S, Janetschek G, Lee BR. Laparoscopic partial nephrectomy: an update on contemporary issues. Urol Clin North Am. 2008; 35:385-96.

11. Hutchinson RW, Werrlein S, Johns DB, et al. An In Vivo Comparison of Hemostatic Gelatin Matrix Products in a Porcine Spleen Biopsy-punch Model. Surg Technol Int. 2015; 27:53-7.

12. Shander A. Financial and clinical outcomes associated with surgical bleeding complications. Surgery. 2007; 142(4 Suppl):S20-5.

13. Boucher BA, Hannon TJ. Blood management: a primer for clinicians.Pharmacotherapy. 2007; 27:1394-411.

14. Pruthi RS, Chun J, Richman M. The use of a fibrin tissue sealant during laparoscopic partial nephrectomy. BJU Int. 2004; 93:813-7.

15. Klingler CH, Remzi M, Marberger M, Janetschek G. Haemostasis in laparoscopy. Eur Urol. 2006; 50:948-56; discussion 956-7. 
16. Palm MD, Altman JS. Topical hemostatic agents: a review. Dermatol Surg. 2008; 34:431-45.

17. Häcker A, Albadour A, Jauker W, et al. Nephron-sparing surgery for renal tumours: acceleration and facilitation of the laparoscopic technique. Eur Urol. 2007; 51:358-65.

18. Johnston WK $3^{\text {rd }}$, Kelel KM, Hollenbeck BK, et al. Acute integrity of closure for partial nephrectomy: comparison of 7 agents in a hypertensive porcine model. J Urol. 2006; 175:2307-11.

19. Dalpiaz O, Neururer R, Bartsch G, Peschel R. Haemostatic sealants in nephron-sparing surgery: what surgeons need to know. BJU Int. 2008; 102:1502-8.
20. Richter F, Schnorr D, Deger S, et al. Improvement of hemostasis in open and laparoscopically performed partial nephrectomy using a gelatin matrix-thrombin tissue sealant (FloSeal). Urology. 2003; 61:73-7.

21. Bak JB, Singh A, Shekarriz B. Use of gelatin matrix thrombin tissue sealant as an effective hemostatic agent during laparoscopic partial nephrectomy. J Urol. 2004; 171:780-2

22. Ramani AP, Desai MM, Steinberg AP, et al. Complications of laparoscopic partial nephrectomy in 200 cases. J Urol. 2005; 173:42-7.

\section{Correspondence}

\section{Faruk Ozgor, MD}

md.farukozgor@yahoo.com

Abdulmuttalip Simsek, MD

simsek76@yahoo.com

Ozgu Aydogdu, MD

Onur Kucuktopcu, MD

Omer Sarilar, MD

Ahmet Yalcin Berberoglu, MD

Mehmet Fatih Ahbulut, MD

Murat Binbay, MD

Department of Urology, Haseki Teaching and Research Hospital

Millet Cad. No: 11, 34096, Fatih, Istanbul, Turkey 